\title{
NUMERICAL STUDY ON THE OPTIMIZATION OF HYDRODYNAMIC PERFORMANCE OF OSCILLATING BUOY WAVE ENERGY CONVERTER
}

\author{
Wenbin Lai \\ Yonghe $\mathrm{Xie}^{*}$ \\ Detang Li \\ Zhejiang Ocean University, China \\ *Corresponding author:xieyh@zjou.edu.cn (Y.Xie)
}

\begin{abstract}
The oscillating buoy wave energy converter (OBWEC) captures wave energy through the undulating movement of the buoy in the waves. In the process of capturing wave energy, the hydrodynamic performance of the buoy plays an important role. This paper designed the "Haida No. 1" OBWEC, in which the buoy adopts a form of swinging motion. In order to further improve the hydrodynamic performance of the buoy, a 2D numerical wave tank (NWT) model is established using ADINA software based on the working principle of the device. According to the motion equation of the buoy in the waves, the influence of the buoy shape, arm length, tilt angle, buoy draft, buoy width, wave height and Power Take-off (PTO) damping on the hydrodynamic performance of the buoy is studied. Finally, a series of physical experiments are performed on the device in a laboratory pool. The experimental results verify the consistency of the numerical results. The research results indicate that the energy conversion efficiency of the device can be improved by optimizing the hydrodynamic performance of the buoy. However, the absorption efficiency of a single buoy for wave energy is limited, so it is very difficult to achieve full absorption of wave energy.
\end{abstract}

Keywords: wave energy converter; hydrodynamic performance; numerical simulation; physical experiment

\section{INTRODUCTION}

In order to alleviate the pressure caused by the energy crisis and protect human health, it is very important to increase the development and utilization of clean and renewable energy $[1,2]$. Among the many renewable energy sources, wave energy is becoming a hot spot in the world's new energy development due to its clean, environmentally friendly, renewable, and huge reserves. Its global reserves are as high as 2.5 billion $\mathrm{kW}$ $[3,4]$. However, the difficulty of wave energy utilization is how to efficiently convert wave energy into electric energy $[5,6]$.

Currently, many types of wave energy converters (WECs) have been developed, and each type of WEC has its own advantages and disadvantages. However, high power generation costs, low energy conversion efficiency, reliability and safety are still the fundamental reasons why these WECs are difficult to commercialize widely $[7,8]$. Considering several factors such as the power generation cost, total efficiency, reliability and safety, the oscillating buoy wave energy converter (OBWEC) has obvious advantages compared with other WECs. OBWEC has the following advantages: simple structure, strong adaptability, convenient maintenance, relatively high energy conversion efficiency, and the core equipment of the device is located above the water surface so that there is no need to worry too much about seawater corrosion and sealing problems $[9,10]$. In recent years, scholars all over the world have conducted a lot of research on OBWEC.

Zannutigh et al. studied the power and hydraulic performance of a floating WEC by changing the mooring system, the wave attack and the device orientation with respect to the incoming waves, and concluded that the CALM mooring system leads always to a larger power production than a spread mooring [11]. Sjolte et al. studied the effects of permanent magnet synchronous generators, inverter, and DC-links on the Power 
Take-off (PTO) capabilities of the device, and found that the reactive control has limited potential for increasing the output of the device [12]. Neary et al. studied the feasibility of applying a classification system for wave resources to WEC classification, and concluded that the WEC response to extreme loads was found to vary considerably within the most energetic of the resource classes examined [13]. De Andrés et al. studied how the geometric tuning of a generic wave energy converter is affected by different climate scenarios, and concluded that the matchability of a device could be achieved via the PTO control or changing the geometric characteristics of a particular device [14]. Bedard et al. studied the impact of different footprint configurations and different mooring systems on the AquaBuOY device, and obtained the performance data of the device under different conditions [15]. Haraguchi et al. studied the feasibility of a point absorber with a tuned inertia mass to increase the power absorption and broaden the effective wave frequency range, and concluded that the energy conversion efficiency of the device can be improved by appropriately adjusting the spring stiffness and generator damping [16]. Homayoun et al. proposed a new concept of near-shore combined renewable energy system, and studied the hydrodynamic performance of WEC under four different buoy shapes, and concluded that the buoy with a curvature inward in the bottom has better hydrodynamic performance [17].

However, the problem of low energy conversion efficiency of OBWEC is still prominent. In order to further improve the energy conversion efficiency of OBWEC, Zhejiang Ocean University designed the "Haida No. 1" OBWEC, in which the buoy adopts a form of swinging motion [18], as shown in Fig. 1. According to the motion equation of the buoy in the wave, this paper studies the influence of the buoy shape, arm length, tilt angle, buoy draft, buoy width, wave height, and PTO damping on the hydrodynamic performance of the buoy. The conclusions can provide meaningful reference value for the design of other buoys.

The remainder of the paper is organized as follows: Section 2 introduces the working principle of the "Haida No. 1" OBWEC. Section 3 derives the motion equation of the buoy in the waves. Section 4 uses ADINA software to establish a 2D numerical wave tank (NWT) model based on the working principle of the device. Section 5 studies the influence of the buoy shape, arm length, tilt angle, buoy draft, buoy width, wave height, and PTO damping on the hydrodynamic performance of the buoy based on the motion equation of the buoy in the waves. Section 6 establishes the physical model of the "Haida No. 1" OBWEC and conducts a series of wave condition experiments on the physical model in a laboratory pool to verify the correctness of the numerical results. Section 7 is the conclusion.

\section{WORKING PRINCIPLE OF THE “HAIDA NO. 1" OBWEC}

Fig. 1 shows the "Haida No. 1" OBWEC designed by our team, which is a variant of the heaving buoy WEC. The device is mainly composed of the wave energy capture system, hydraulic transmission system, energy output system and control and protection system.

The working principle of the device is as follows: Firstly, the buoy moves up and down with the waves, and then captures wave energy from the waves and converts it into its own mechanical energy. Secondly, the buoy pushes the hydraulic piston to move up and down, and the hydraulic piston then drives the hydraulic cylinder to do work, thereby completing the conversion of the mechanical energy of the buoy into hydraulic energy. Thirdly, unstable hydraulic energy enters the accumulator, and after being adjusted by the accumulator, stable hydraulic energy is output. Finally, the stable hydraulic energy enters the hydraulic motor and drives the hydraulic motor to work, thereby driving the generator to convert the hydraulic energy into electrical energy.

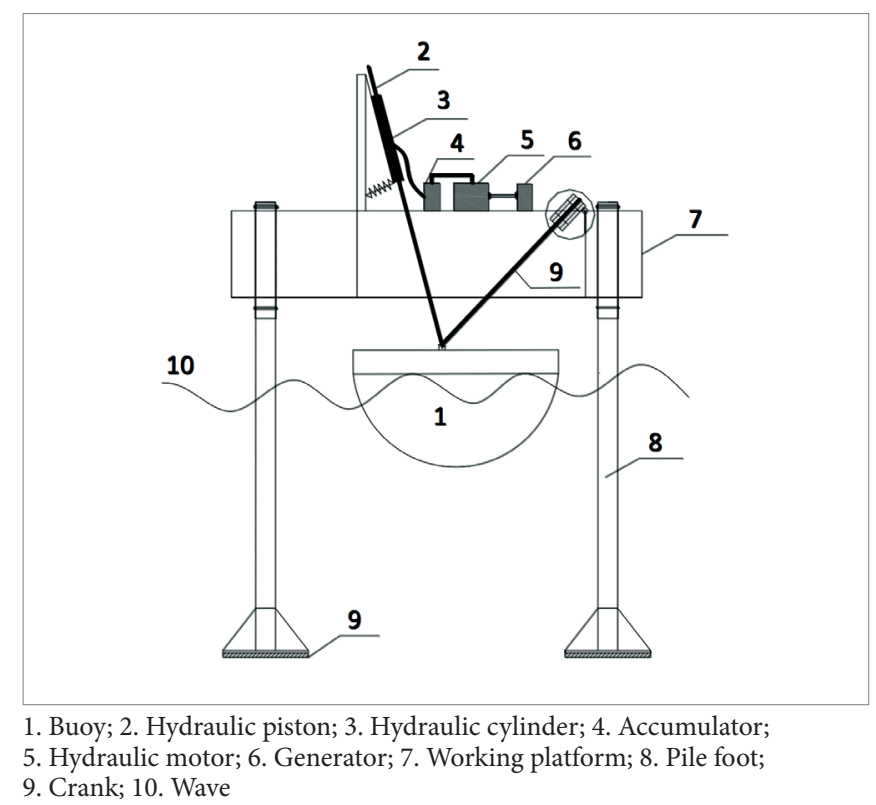

Fig. 1. "Haida No. 1" OBWEC

\section{MOTION EQUATION OF BUOY IN THE WAVES}

As shown in Fig. 2, the wave energy capture system consists of a buoy and an arm. One end of the arm is fixedly connected to the buoy, and the other end of the arm is fixed at point $\mathrm{O}$ by a hinge. The buoy and arm form

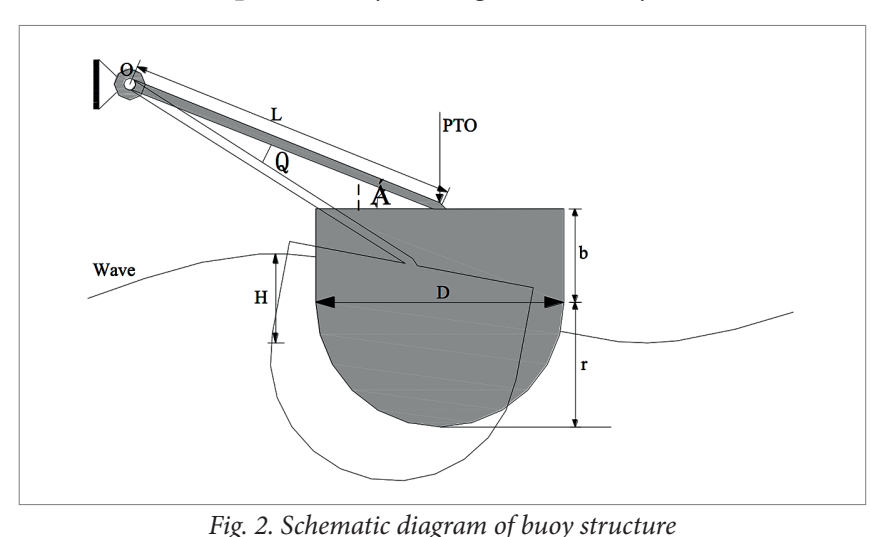


a single-degree-of-freedom system, which is represented by its angular motion, $\theta$. A linear PTO damper acts on the centre of the upper surface of the buoy. In regular wave theory, the motion equation of the buoy in the waves can be obtained by superimposing the effect of the PTO damping and incident wave on the buoy [19]:

$$
\left(J+J_{a}\right) \ddot{\theta}=T_{\text {Arch }}-T_{G}+T_{r a d}-T_{P T O}+T_{\text {ext }}
$$

where $J$ is the moment of inertia of the buoy and arm, $J_{a}$ is the additional moment of inertia caused by the movement of the buoy, $\ddot{\theta}$ is the angular acceleration when the arm moves, $T_{\text {Arch }}$ is the torque caused by Archimedes force, $T_{G}$ is the torque caused by gravity, $T_{\text {rad }}$ is the radiated wave torque caused by the radiated wave, $T_{P T O}$ is the load torque caused by the PTO damping, $T_{e x t}$ is the exciting torque caused by the incident wave.

By identifying the terms in Eq. (1), the following wellknown expressions are obtained:

$$
\ddot{\theta}=\frac{T_{r e s}+T_{r a d}-T_{P T O}+T_{e x t}}{\left(J+J_{a}\right)}
$$

where $T_{r e s}$ is the hydrostatic restoring torque.

\section{EXCITING TORQUE}

The exciting torque $T_{\text {ext }}$ is the torque of an incident wave acting on a buoy held fixed, which can be obtained by the following formula:

$$
T_{\text {ext }}=\int_{-r}^{b} P(L \sin \alpha+z) d z
$$

where $P$ is the pressure of the incident wave on the buoy, $L$ is the arm length, $\alpha$ is the tilt angle of the arm to the horizontal axis, $b$ is the buoy freeboard, and $r$ is the buoy draft.

\section{HYDROSTATIC RESTORING TORQUE}

The torque $T_{\text {Arch }}$ is equal to the Archimedes force multiplied by the effective arm length:

$$
T_{\text {Arch }}=V_{\text {disp }} \rho g L \cos \left(\frac{\pi}{2}-\alpha+\theta\right)
$$

where $V_{\text {disp }}$ is the volume of the submerged part of the buoy, $\rho$ is the density of water, and $g$ is the gravitational acceleration.

The torque $T_{G}$ is equal to the weight of the buoy multiplied by the effective arm length:

$$
T_{G}=m g L \cos \left(\frac{\pi}{2}-\alpha+\theta\right)
$$

where $m$ is the mass of the buoy.

Therefore, the hydrostatic restoring torque is:

$$
T_{r e s}=T_{\text {Arch }}-T_{G}=\left(V_{\text {disp }} \rho-m\right) g L \cos \left(\frac{\pi}{2}-\alpha+\theta\right)
$$

\section{LOAD TORQUE}

The load torque $T_{\text {РТО }}$ is caused by the PTO force acting on the buoy. The PTO force can be obtained by the following relationship:

$$
F_{P T O}=C \dot{\theta} L \sin \left(\frac{\pi}{2}-\alpha+\theta\right)
$$

where $C$ is the PTO damping coefficient.

Hence, the load torque is:

$$
T_{P T O}=C \dot{\theta} L^{2} \sin ^{2}\left(\frac{\pi}{2}-\alpha+\theta\right)
$$

\section{RADIATING WAVE TORQUE}

When the buoy moves in the waves with frequency $\omega$, a radiating wave is generated. The radiating wave acting on the buoy will produce radiated wave torque, which can be described as:

$$
T_{\text {rad }}=\left(-J_{a} \dot{\omega}-b_{h y d} \omega\right) L \cos \left(\frac{\pi}{2}-\alpha+\theta\right)
$$

where $b_{\text {hyd }}$ is the hydrodynamic damping coefficient.

According to the above motion equation of the buoy in the waves, the factors that affect the hydrodynamic performance of the buoy mainly include the buoy shape, arm length, tilt angle, buoy draft, buoy width, wave height, and PTO damping.

\section{ESTABLISHMENT AND VERIFICATION OF NUMERICAL MODEL}

\section{ESTABLISHMENT OF NUMERICAL MODEL}

According to the working principle of the "Haida No. 1" OBWEC, the numerical model of the buoy structure and corresponding fluid model of the computational domain are established respectively using ADINA software as shown in Fig. 3. In the numerical model of the buoy structure, in order to enable the buoy to rotate freely around the point $O$, a contact group, contact surface, contact pair, and friction system are defined at the hinge to control the movement of the buoy. In the fluid model of the computational domain, the upper boundary of the flow field is set as a free surface, and the lower boundary is set as a fixed wall. The left boundary is set as the incident wave boundary, and the right boundary is set as the fixed wall. In order to avoid the influence of the reflected wave on the buoy's movement, the work is stopped before the reflected wave reaches the position of the buoy. In the flow field, the vertical grid resolution gradually increases from the fixed wall to the free surface; in the area behind the buoy, the horizontal grid resolution gradually decreases. The initial time step is set to $0.002 \mathrm{~s}$, which can ensure that the implicit solver has sufficient accuracy [20]. 


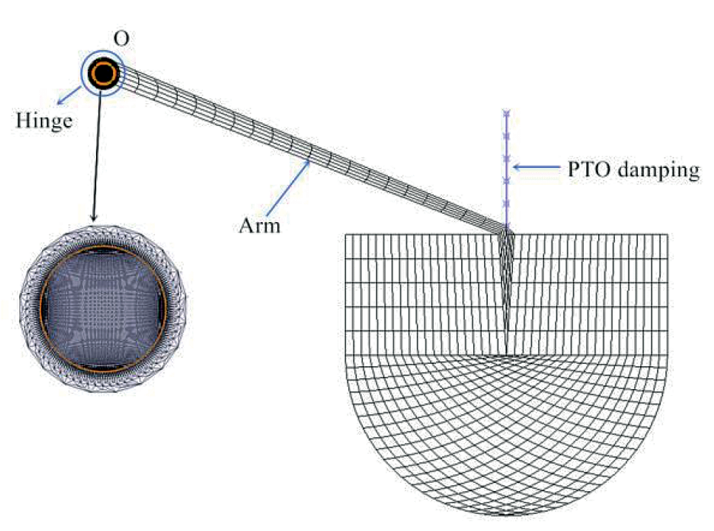

(a) Buoy's structure model

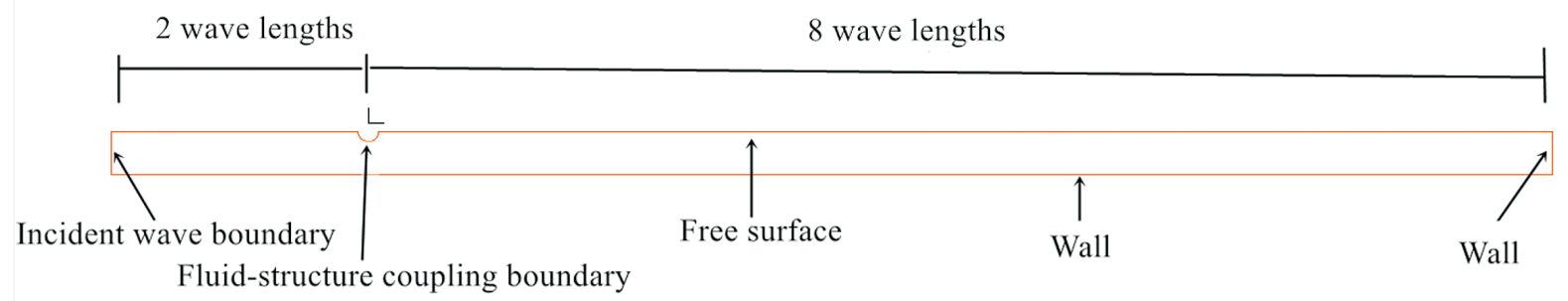

(b) Fluid model of the computational domain

Fig. 3. Two-dimensional numerical model

\section{VERIFICATION OF NUMERICAL RESULTS}

Fig. 4 shows the time process of the incident wave height at the position of the buoy between the theoretical and numerical results under different wave periods, where the Z-displacement represents the distance from the wave surface to the horizontal plane. The water depth in the NWT is $10 \mathrm{~m}$. It can be seen that no matter whether the wave period is $3.8 \mathrm{~s}$ or $4.2 \mathrm{~s}$, there is a good agreement between the theoretical and numerical results, which verifies the accuracy of the NWT.

\section{OPTIMIZATION OF HYDRODYNAMIC PERFORMANCE OF THE BUOY}

\section{OPTIMIZING TARGET PARAMETERS}

The optimization target parameter of this paper is mainly the capture width ratio $\beta$ of the buoy. The capture width ratio $\beta$ of the buoy can be calculated by the following equation:

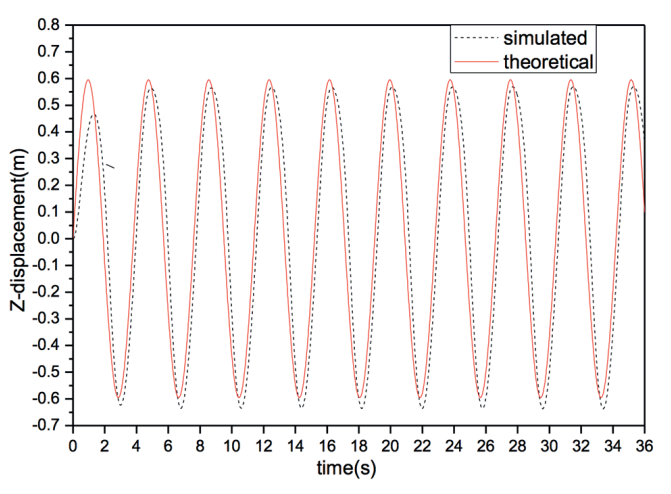

(a) Comparison of the incident wave height when the wave period $T=3.8 s$

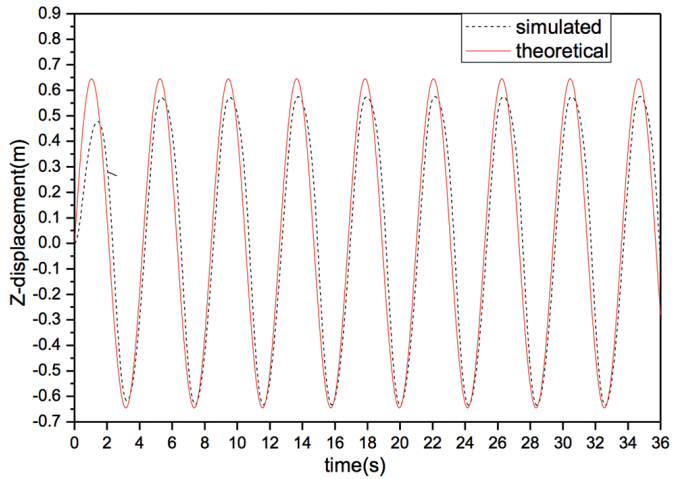

(b) Comparison of the incident wave height when the wave period $T=4.2 s$.

Fig. 4. Verification of numerical results 


$$
\beta=\frac{P_{b}}{P_{\text {wave }}}
$$

where $P_{b}$ is the average output power of the buoy, and is the average power of the incident wave on the buoy.

$$
\begin{gathered}
P_{b}=\frac{\int_{t_{1}}^{t_{2}} C \bar{v}^{2}}{t_{2}-t_{1}} \\
P_{\text {wave }}=\frac{1}{32 \pi} \rho g^{2} H^{2} T \bar{D} \approx 981 H^{2} T D
\end{gathered}
$$

where $\bar{v}$ is the heave speed of the buoy, $H$ is the wave height, $T$ is the wave period, and $\bar{D}$ is the lateral width of the buoy.

\section{INFLUENCE OF ARM LENGTH ON THE HYDRODYNAMIC PERFORMANCE OF THE BUOY}

In order to study the influence of the arm length $L$ on the hydrodynamic performance of the buoy, the arm length $L$ of the buoy is set to $1 \mathrm{~m}, 2 \mathrm{~m}, 3 \mathrm{~m}, 4 \mathrm{~m}, 5 \mathrm{~m}, 6 \mathrm{~m}, 7 \mathrm{~m}$, and $8 \mathrm{~m}$, respectively. The upper half of the buoy is a rectangle with a length of $4 \mathrm{~m}$ and a height of $2 \mathrm{~m}$, and the lower half is a semicircle with a radius of $2 \mathrm{~m}$. The tilt angle $\alpha$ is set to $20^{\circ}$, and the PTO damping coefficient $C=5000 \mathrm{~N} \cdot \mathrm{s} / \mathrm{m}$. When the wave period is $4.2 \mathrm{~s}$, the heave Response Amplitude Operator (RAO) and capture width ratio of the buoy under different arm lengths are shown in Fig. 5.

It can be seen from Fig. 5 that when other parameters remain unchanged, as the arm length $L$ increases, the heave RAO and capture width ratio of the buoy first increase, and then gradually stabilize. When the arm length $L$ is less than $5 \mathrm{~m}$,

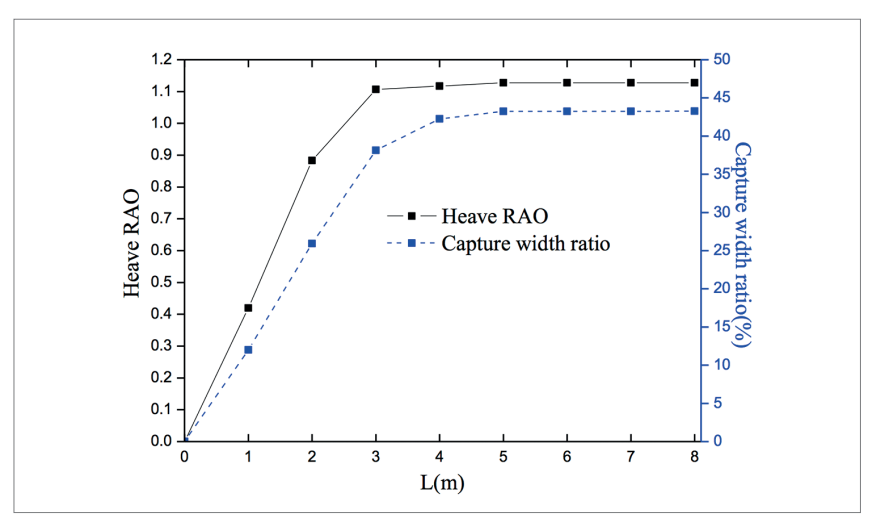

Fig. 5. Hydrodynamic performance of buoys under different arm lengths

the arm length has a greater influence on the hydrodynamic performance of the buoy. At this time, its hydrodynamic performance is basically proportional to the arm length. When the arm length $L$ is greater than $5 \mathrm{~m}$, the hydrodynamic performance of the buoy changes very little with the increase of the arm length, and finally remains unchanged.

The above conclusions demonstrate that the arm length has a great influence on the hydrodynamic performance of the buoy, especially when the arm length $L$ is small. When the arm length reaches a certain value, its influence on the hydrodynamic performance of the buoy can be ignored. Therefore, when designing the arm length, it is necessary to choose a reasonable length to avoid wasting space with too long an arm, or reducing the hydrodynamic performance of the buoy with too short an arm.

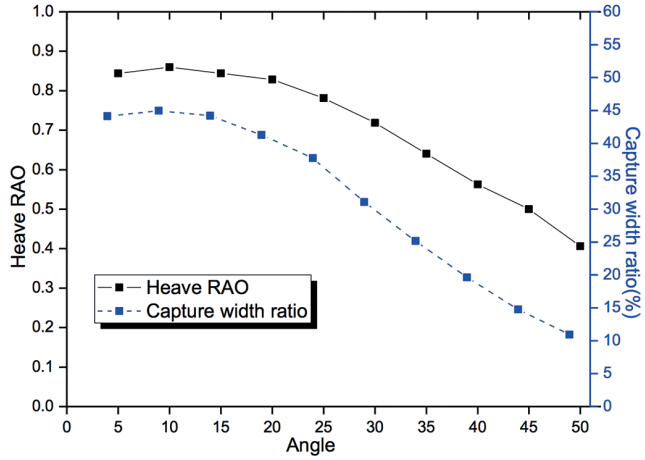

(a) The hydrodynamic performance of the buoy at $T=3.4 \mathrm{~s}$

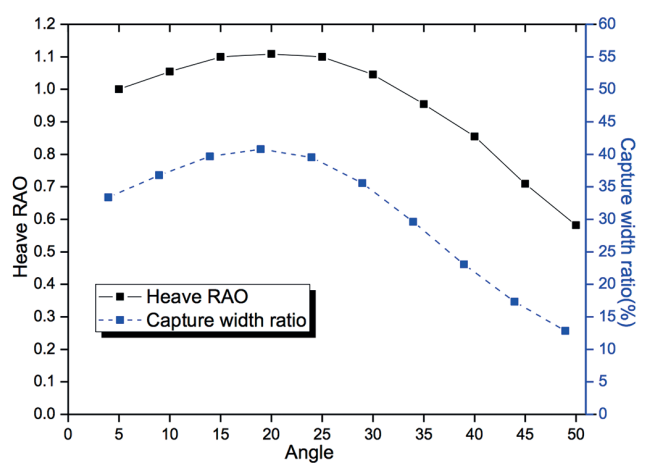

(c) The hydrodynamic performance of the buoy at $T=4.2 \mathrm{~s}$.

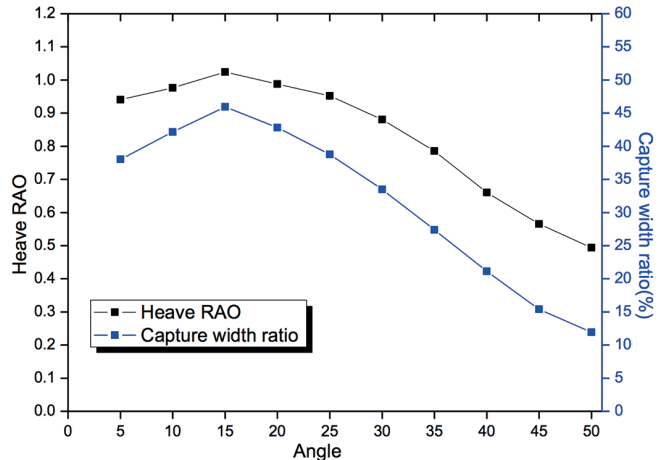

(b) The hydrodynamic performance of the buoy at $T=3.8 \mathrm{~s}$.

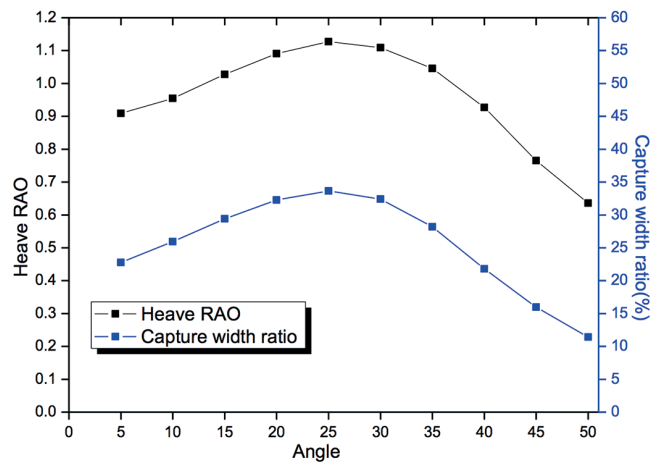

(d) The hydrodynamic performance of the buoy at $T=4.6 \mathrm{~s}$.

Fig. 6. Hydrodynamic performance of buoys under different tilt angles 


\section{INFLUENCE OF TILT ANGLE ON THE HYDRODYNAMIC PERFORMANCE OF THE BUOY}

In order to study the influence of the tilt angle $\alpha$ on the hydrodynamic performance of the buoy, the arm length $L$ is set to $5 \mathrm{~m}$, and the other parameters are the same as above. The tilt angles $\alpha$ are set to $5^{\circ}, 10^{\circ}, 15^{\circ}, 20^{\circ}, 25^{\circ}, 30^{\circ}, 35^{\circ}, 40^{\circ}$, $45^{\circ}$, and $50^{\circ}$, respectively. The influence of different tilt angles on the hydrodynamic performance of the buoy under wave periods of $3.4 \mathrm{~s}, 3.8 \mathrm{~s}, 4.2 \mathrm{~s}$ and $4.6 \mathrm{~s}$ are studied respectively as shown in Fig. 6.

When the wave period is $3.4 \mathrm{~s}$, it can be seen from Fig. $6 \mathrm{a}$ that as the tilt angle increases, the heave RAO and capture width ratio of the buoy first increase and then decrease, and the change trend in the heave RAO and capture width ratio of the buoy is consistent. When the tilt angle is less than $10^{\circ}$, as the tilt angle increases, the heave RAO and capture width ratio of the buoy gradually increase. When the tilt angle is greater than $10^{\circ}$, as the tilt angle increases, the heave RAO and capture width ratio of the buoy gradually decrease. When the tilt angle is $10^{\circ}$, the heave $\mathrm{RAO}$ and capture width ratio of the buoy reach the maximum. At this time, its hydrodynamic performance is the best, and the maximum capture width ratio of the buoy is $44.97 \%$.

Under other wave periods, the heave RAO and capture width of the buoy have the same changing trend as above. For the $3.8 \mathrm{~s}$ wave period, when the tilt angle is $15^{\circ}$, the heave RAO and capture width of the buoy reach the maximum, and the maximum capture width ratio is $49.56 \%$. For the $4.2 \mathrm{~s}$ wave period, when the tilt angle is $20^{\circ}$, the heave RAO and capture width of the buoy reach the maximum, and the maximum capture width ratio is $40.77 \%$. For the $4.6 \mathrm{~s}$ wave period, when the tilt angle is $20^{\circ}$, the heave RAO and capture width of the buoy reach the maximum, and the maximum capture width ratio is $33.64 \%$.

The above conclusions demonstrate that the tilt angle has a greater impact on the hydrodynamic performance of the buoy. For the same wave period, as the tilt angle increases, the capture width ratio of the buoy first increases and then decreases. Within a certain wave period, as the wave period increases, the optimal tilt angle also increases.

\section{INFLUENCE OF BUOY SHAPE ON THE HYDRODYNAMIC PERFORMANCE OF THE BUOY}

In order to study the influence of the buoy shape on the hydrodynamic performance of the buoy, the arm length $L$ is set to $5 \mathrm{~m}$, the tilt angle $\alpha$ is $20^{\circ}$, the wave period is $4.2 \mathrm{~s}$, and the other parameters are the same as above. Keeping the buoy draft the same $r=2 \mathrm{~m}$, and the buoy width the same $D=4 \mathrm{~m}$, four different structures of the buoy shape and the corresponding fluid models are established by ADINA software as shown in Fig. 7.

Fig. 8a shows the heave RAO of different buoy shapes under the same wave period. From the bar graph, the heave RAO of buoy shape 2 is the largest, followed by buoy shape 3, buoy

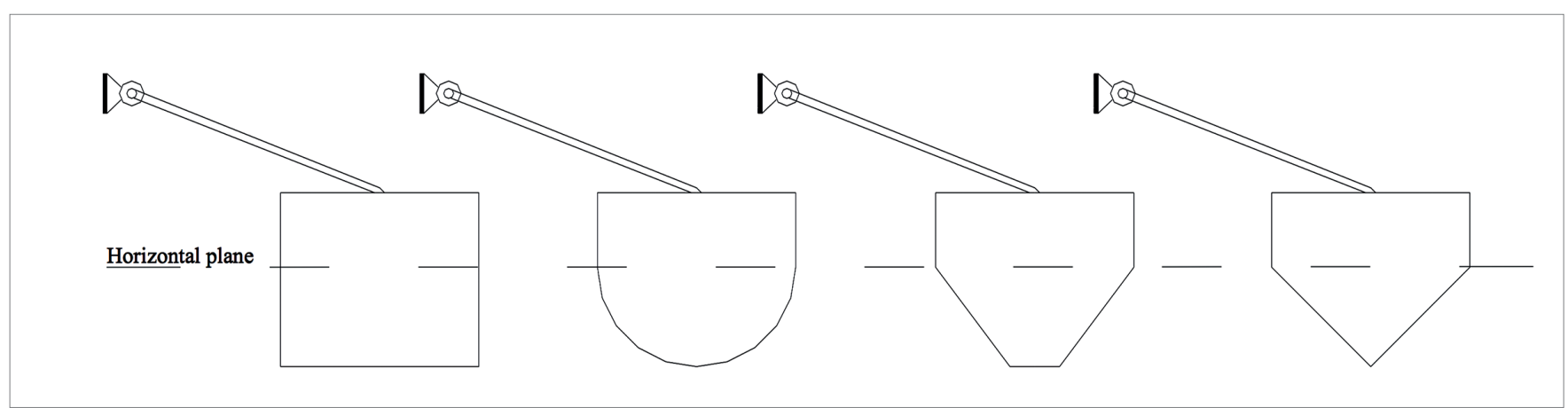

Fig. 7. Schematic diagram of buoy structure with different buoy shapes

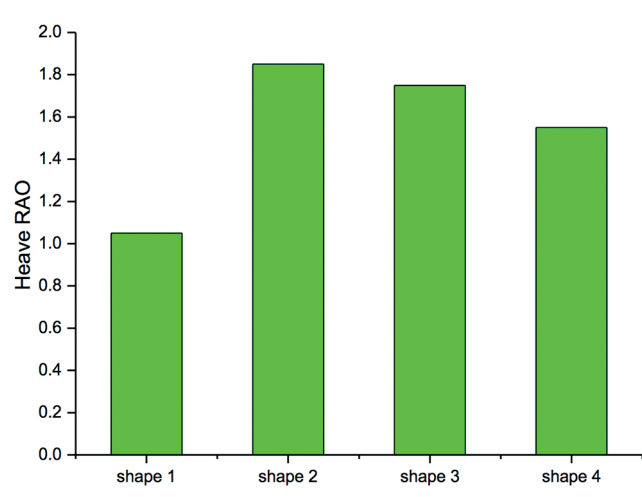

(a) Heave RAO with different buoy shapes

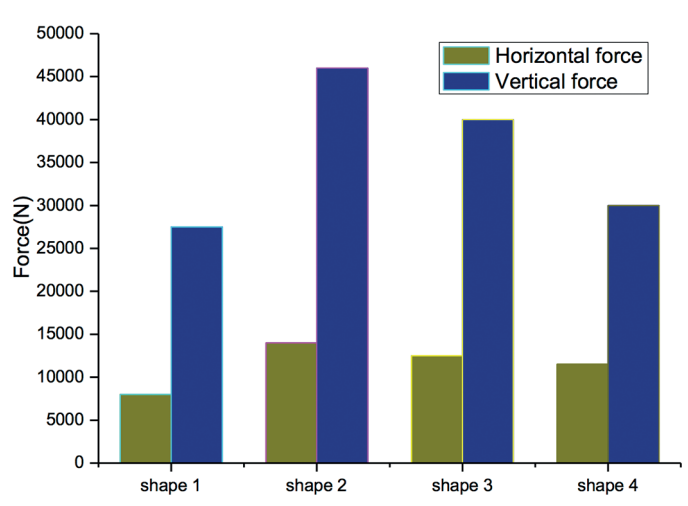

(b) Horizontal and vertical forces of different buoy shapes

Fig. 8. Hydrodynamic performance of buoys under different buoy shapes 
shape 4 , and buoy shape 1 . Fig. $8 \mathrm{~b}$ shows the magnitude of the combined force received by different buoy shapes in the horizontal and vertical directions under the same wave. From the bar graph, the horizontal combined force and vertical combined force received by buoy shape 2 are both the largest, followed by buoy shape 3 , buoy shape 4 , and buoy shape 1 . In the horizontal direction, the magnitude of the combined force on different buoy shapes does not change much; however, in the vertical direction, it changes greatly. According to Eq. (3), it can be seen that when the buoy draft is the same, the wave exciting force acting on the buoy is the same. Since the wave exciting force is the main external force received by the buoy in the horizontal direction, it causes the combined force received by the buoy in this direction to change very little. In the vertical direction, the buoy is not only subjected to the wave exciting force, buoyancy and gravity, but also subjected to fluid resistance. Since the fluid resistance of the buoy shape 2 is the smallest, the combined force received by it is the largest.

The above conclusions demonstrate that buoy shape 2 has better hydrodynamic performance than the other three buoy shapes under the same wave.

\section{INFLUENCE OF BUOY WIDTH ON THE HYDRODYNAMIC PERFORMANCE OF THE BUOY}

In order to study the influence of the buoy width $D$ on the hydrodynamic performance of the buoy, the buoy draft $r$ is set to $2 \mathrm{~m}$, the arm length $L$ is $5 \mathrm{~m}$, the tilt angle $\alpha$ is $20^{\circ}$, and the other parameters are the same as above. We take two wave periods, $T=3.4 \mathrm{~s}$ and $3.8 \mathrm{~s}$, and the corresponding wavelengths are $18 \mathrm{~m}$ and $22 \mathrm{~m}$ respectively. The buoy widths are set to $2 \mathrm{~m}, 3 \mathrm{~m}, 4 \mathrm{~m}, 5 \mathrm{~m}, 6 \mathrm{~m}$, and $7 \mathrm{~m}$, respectively. The influence of different buoy widths on the hydrodynamic performance of the buoy under the PTO damping coefficient of $2500 \mathrm{~N} \cdot \mathrm{s} / \mathrm{m}, 5000 \mathrm{~N} \cdot \mathrm{s} / \mathrm{m}, 7500 \mathrm{~N} \cdot \mathrm{s} / \mathrm{m}, 10000 \mathrm{~N} \cdot \mathrm{s} / \mathrm{m}$, $12500 \mathrm{~N} \cdot \mathrm{s} / \mathrm{m}, 15000 \mathrm{~N} \cdot \mathrm{s} / \mathrm{m}, 17500 \mathrm{~N} \cdot \mathrm{s} / \mathrm{m}$, and $20000 \mathrm{~N} \cdot \mathrm{s} / \mathrm{m}$ is studied respectively as shown in Fig. 9.

Fig. 9a shows the influence of different buoy widths on the hydrodynamic performance of the buoy for wave period
$T=3.4 \mathrm{~s}$. It can be seen from the curve in the figure that for the buoy width of $2 \mathrm{~m}$, when the PTO damping coefficient $C=7500 \mathrm{~N} \cdot \mathrm{s} / \mathrm{m}$, the capture width ratio of the buoy reaches the maximum, and the maximum capture width ratio is $37.94 \%$. When the PTO damping coefficient is less than $7500 \mathrm{~N} \cdot \mathrm{s} / \mathrm{m}$, as the PTO damping coefficient increases, the capture width ratio of the buoy increases. When the PTO damping coefficient is greater than $7500 \mathrm{~N} \cdot \mathrm{s} / \mathrm{m}$, as the $P T O$ damping coefficient increases, the capture width ratio of the buoy decreases. For other buoy widths, the change trend of the buoy's capture width ratio with the PTO damping coefficient is the same as above. When the buoy widths are $3 \mathrm{~m}, 4 \mathrm{~m}, 5 \mathrm{~m}$, $6 \mathrm{~m}$, and $7 \mathrm{~m}$, the corresponding optimal capture width ratios are $41.57 \%, 41.62 \%, 39.68 \%, 35.95 \%$, and $31.61 \%$, respectively.

Fig. 9b shows the influence of different buoy widths on the hydrodynamic performance of the buoy for wave period $T=3.8$ s. It can be seen from the curve in the figure that when the buoy widths are $2 \mathrm{~m}, 3 \mathrm{~m}, 4 \mathrm{~m}, 5 \mathrm{~m}, 6 \mathrm{~m}$, and $7 \mathrm{~m}$, the corresponding optimal capture width ratios are $33.71 \%$, $38.80 \%, 40.41 \%, 41.22 \%, 35.85 \%$, and $32.10 \%$, respectively.

From the above conclusions, under the same wave period, as the buoy width increases, the buoy's maximum capture width first increases and then decreases. For the wave with a period of $3.4 \mathrm{~s}$, the corresponding wavelength is $18 \mathrm{~m}$, and the capture width ratio reaches the maximum when the buoy width is $4 \mathrm{~m}$. For the wave period of $3.8 \mathrm{~s}$, the corresponding wavelength is $22 \mathrm{~m}$, and the capture width ratio reaches the maximum when the buoy width is $5-\mathrm{m}$. From the above, when the ratio of the wavelength to the buoy width is between 4 and 5, the buoy's capture width ratio is the largest.

\section{INFLUENCE OF BUOY DRAFT ON THE HYDRODYNAMIC PERFORMANCE OF THE BUOY}

In order to study the influence of the buoy draft $r$ on the hydrodynamic performance of the buoy, the arm length $L$ is set to $5 \mathrm{~m}$, the buoy width $D$ is $4 \mathrm{~m}$, the tilt angle $\alpha$ is $20^{\circ}$, and the other parameters are the same as above. When the wave periods are $3.4 \mathrm{~s}$ and $4.2 \mathrm{~s}$, and the corresponding wave heights

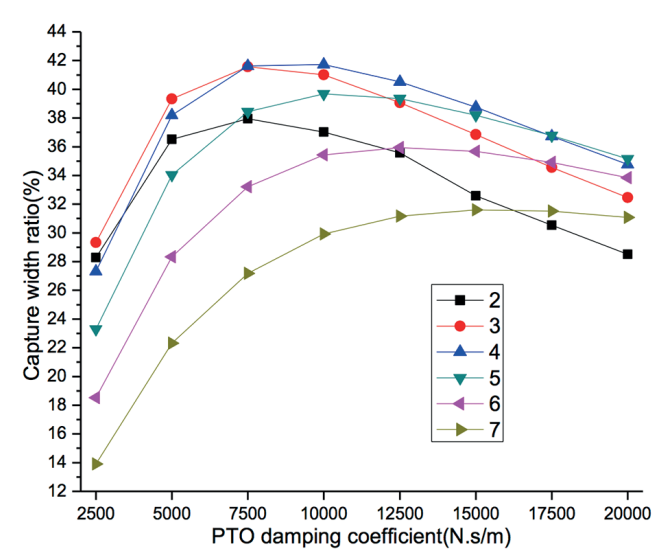

(a) The hydrodynamic performance of the buoy at $T=3.4 \mathrm{~s}$

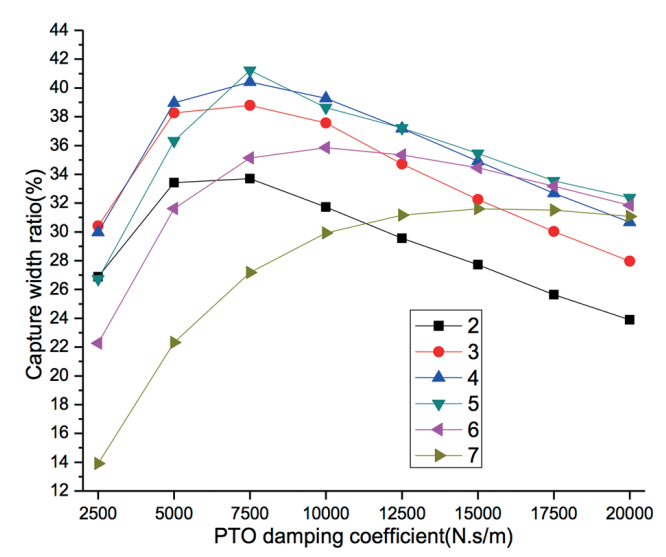

(b) The hydrodynamic performance of the buoy at $T=3.8 \mathrm{~s}$

Fig. 9. Hydrodynamic performance of buoys under different buoy widths 


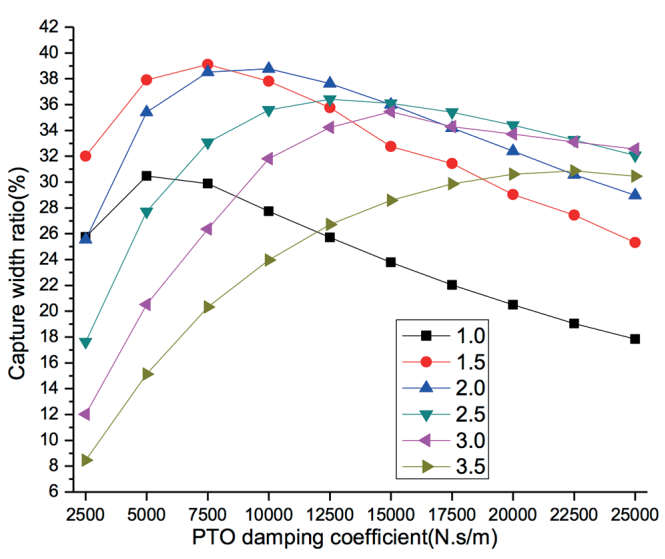

(a) The hydrodynamic performance of the buoy at $T=3.4 \mathrm{~s}$

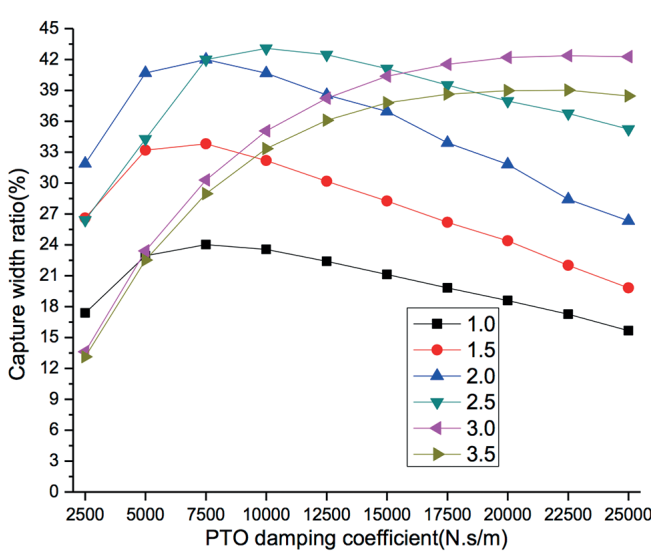

(b) The hydrodynamic performance of the buoy at $T=4.2 \mathrm{~s}$

Fig. 10. Hydrodynamic performance of buoys under different buoy drafts

are $0.51 \mathrm{~m}$ and $0.94 \mathrm{~m}$, respectively, the buoy drafts are set to $1.0 \mathrm{~m}, 1.5 \mathrm{~m}, 2.0 \mathrm{~m}, 2.5 \mathrm{~m}, 3.0 \mathrm{~m}$, and $3.5 \mathrm{~m}$, respectively. The influence of different buoy drafts on the hydrodynamic performance of the buoy under the PTO damping coefficients of $2500 \mathrm{~N} \cdot \mathrm{s} / \mathrm{m}, 5000 \mathrm{~N} \cdot \mathrm{s} / \mathrm{m}, 7500 \mathrm{~N} \cdot \mathrm{s} / \mathrm{m}, 10000 \mathrm{~N} \cdot \mathrm{s} / \mathrm{m}$, $12500 \mathrm{~N} \cdot \mathrm{s} / \mathrm{m}, 15000 \mathrm{~N} \cdot \mathrm{s} / \mathrm{m}, 17500 \mathrm{~N} \cdot \mathrm{s} / \mathrm{m}$, and $20000 \mathrm{~N} \cdot \mathrm{s} / \mathrm{m}$ is studied respectively as shown in Fig. 10.

Fig. 10a shows the influence of different buoy drafts on the hydrodynamic performance of the buoy for wave period $T=3.4$ s. It can be seen from the curve in the figure that for the buoy draft of $1.0 \mathrm{~m}$, when the PTO damping coefficient $C=5000 \mathrm{~N} \cdot \mathrm{s} / \mathrm{m}$, the capture width ratio of the buoy reaches the maximum, and the maximum value is $30.48 \%$. When the PTO damping coefficient is less than $5000 \mathrm{~N} \cdot \mathrm{s} / \mathrm{m}$, as the PTO damping coefficient increases the capture width ratio of the buoy increases. When the PTO damping coefficient is greater than $5000 \mathrm{~N} \cdot \mathrm{s} / \mathrm{m}$, as the PTO damping coefficient increases the capture width ratio of the buoy decreases. For other buoy drafts, the change trend of the buoy's capture width ratio with the PTO damping coefficient is the same as above. When the buoy drafts are $1.5 \mathrm{~m}, 2.0 \mathrm{~m}, 2.5 \mathrm{~m}$, $3.0 \mathrm{~m}$, and $3.5 \mathrm{~m}$, the corresponding optimal capture width ratios are $33.81 \%, 42.01 \%, 43.07 \%, 42.36 \%$, and $39.02 \%$, respectively.

Fig. 10b shows the influence of different buoy drafts on the hydrodynamic performance of the buoy for wave period $T=4.2 \mathrm{~s}$. It can be seen from the curve in the figure that when the buoy drafts are $1.0 \mathrm{~m}, 1.5 \mathrm{~m}, 2.0 \mathrm{~m}, 2.5 \mathrm{~m}, 3.0 \mathrm{~m}$, and $3.5 \mathrm{~m}$, the corresponding optimal capture width ratios are $24.03 \%, 33.81 \%, 42.01 \%, 43.07 \%, 42.36 \%$, and $39.02 \%$, respectively.

From the above conclusions, for the wave with a period of $3.4 \mathrm{~s}$ and a wave height of $0.51 \mathrm{~m}$, the capture width ratio of the buoy reaches the maximum when the buoy draft is about $1.5 \mathrm{~m}$, and the maximum is $39.11 \%$. For the wave with a period of $4.2 \mathrm{~s}$ and a wave height of $0.94 \mathrm{~m}$, the capture width ratio of the buoy reaches the maximum when the buoy draft is about $2.5 \mathrm{~m}$, and the maximum value is $43.07 \%$. Under the same wave period, as the buoy draft increases the maximum capture width ratio of the buoy first increases and then decreases. When the ratio of the buoy draft to the wave height is about 2.75 , the buoy's capture width ratio is the largest.

\section{INFLUENCE OF WAVE HEIGHT ON THE HYDRODYNAMIC PERFORMANCE OF THE BUOY}

In order to study the influence of the wave height $H$ on the hydrodynamic performance of the buoy, the buoy draft $r$ is kept unchanged, the arm length $L$ is $5 \mathrm{~m}$, the buoy width is $4 \mathrm{~m}$, the buoy draft $r$ is $2 \mathrm{~m}$, the tilt angle $\alpha$ is $20^{\circ}$, and the wave periods are $3.4 \mathrm{~s}$ and $4.2 \mathrm{~s}$ respectively. When the wave period is $3.4 \mathrm{~s}$, the wave heights are set to $0.67 \mathrm{~m}, 0.74 \mathrm{~m}$, $0.83 \mathrm{~m}, 0.91 \mathrm{~m}, 0.97 \mathrm{~m}$ and $1.05 \mathrm{~m}$, respectively. When the wave period is $4.2 \mathrm{~s}$, the wave heights are set to $0.94 \mathrm{~m}, 1.09 \mathrm{~m}$, $1.24 \mathrm{~m}, 1.38 \mathrm{~m}, 1.51 \mathrm{~m}$ and $1.64 \mathrm{~m}$, respectively. The influence of different wave heights on the hydrodynamic performance of the buoy under the PTO damping coefficient of $5000 \mathrm{~N} \cdot \mathrm{s} / \mathrm{m}$, $6000 \mathrm{~N} \cdot \mathrm{s} / \mathrm{m}, 7000 \mathrm{~N} \cdot \mathrm{s} / \mathrm{m}, 8000 \mathrm{~N} \cdot \mathrm{s} / \mathrm{m}, 9000 \mathrm{~N} \cdot \mathrm{s} / \mathrm{m}$, and $10000 \mathrm{~N} \cdot \mathrm{s} / \mathrm{m}$ is studied, respectively as shown in Fig. 11.

Fig. 11a shows the influence of different wave heights on the hydrodynamic performance of the buoy when the wave period is $3.4 \mathrm{~s}$. It can be seen from the curve in the figure that for the wave height of $0.67 \mathrm{~m}$, when the PTO damping coefficient $=9000$, the capture width ratio of the buoy reaches the maximum, and the maximum value is $38.23 \%$. When the PTO damping coefficient is less than 9000, as the PTO damping coefficient increases the buoy's capture width ratio increases. When the PTO damping coefficient is greater than 9000, as the PTO damping coefficient increases the buoy's capture width ratio decreases. For other wave heights, the variation trend of the buoy's capture width ratio with the PTO damping coefficient is the same as above. When the wave heights are $0.74 \mathrm{~m}, 0.83 \mathrm{~m}, 0.91 \mathrm{~m}, 0.97 \mathrm{~m}$, and 1.05 $\mathrm{m}$, the maximum capture width ratio of the buoy is $40.46 \%$, $40.07 \%$, 39.71\%, 39.37\%, and $39.15 \%$, respectively. And the PTO damping coefficient corresponding to the maximum buoy capture width ratio is 9000 in all cases. 


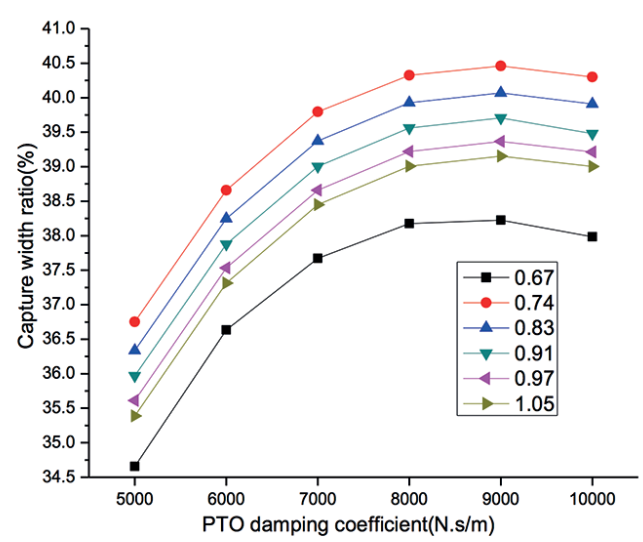

(a) The hydrodynamic performance of the buoy at $T=3.4 \mathrm{~s}$

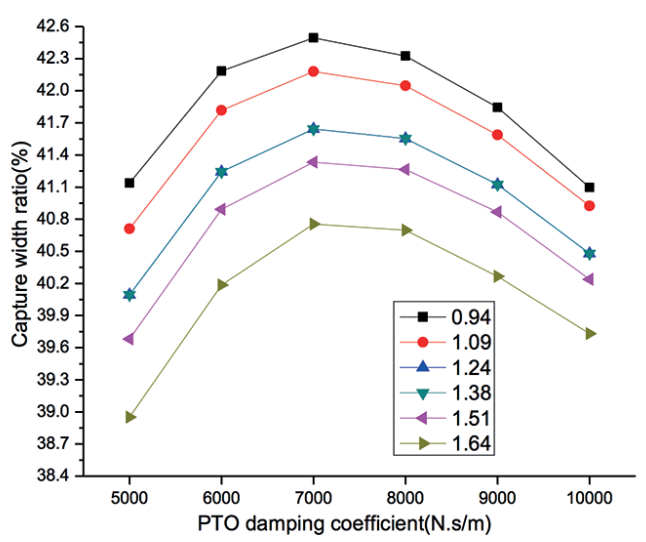

(b) The hydrodynamic performance of the buoy at $T=4.2 \mathrm{~s}$

Fig. 11. Hydrodynamic performance of buoys under different wave heights

Fig. 11b shows the influence of different wave heights on the hydrodynamic performance of the buoy when the wave period is $4.2 \mathrm{~s}$. It can be seen from the curve in the figure that when the wave heights are $0.94 \mathrm{~m}, 1.09 \mathrm{~m}, 1.24 \mathrm{~m}, 1.38 \mathrm{~m}, 1.51 \mathrm{~m}, 1.64 \mathrm{~m}$, the corresponding optimal capture width ratios are $42.50 \%$, $42.18 \%, 41.64 \%, 41.33 \%, 41.22 \%$, and $40.75 \%$, respectively. And the PTO damping coefficient corresponding to the maximum buoy capture width ratio is $7000 \mathrm{~N} \cdot \mathrm{s} / \mathrm{m}$ in all cases.

From the above conclusions, under the same wave period, as the wave height increases, the buoy's capture width ratio first increases and then decreases. The maximum capture width ratio of the buoy appears when the ratio of the buoy draft to the wave height is about 2.75 , which is consistent with the conclusion of the previous section on the influence of the buoy draft on the hydrodynamic performance of the buoy. For the wave period of $3.4 \mathrm{~s}$, the optimum PTO damping coefficient corresponding to the maximum capture width ratio of the buoy is $C=9000 \mathrm{~N} \cdot \mathrm{s} / \mathrm{m}$ in all cases. For the wave period of $4.2 \mathrm{~s}$, the optimum PTO damping coefficient corresponding to the maximum capture width ratio of the buoy is all $C=7000 \mathrm{~N} \cdot \mathrm{s} / \mathrm{m}$ in all cases. The above shows that the optimal PTO damping coefficient is only related to the wave period, not the wave height.

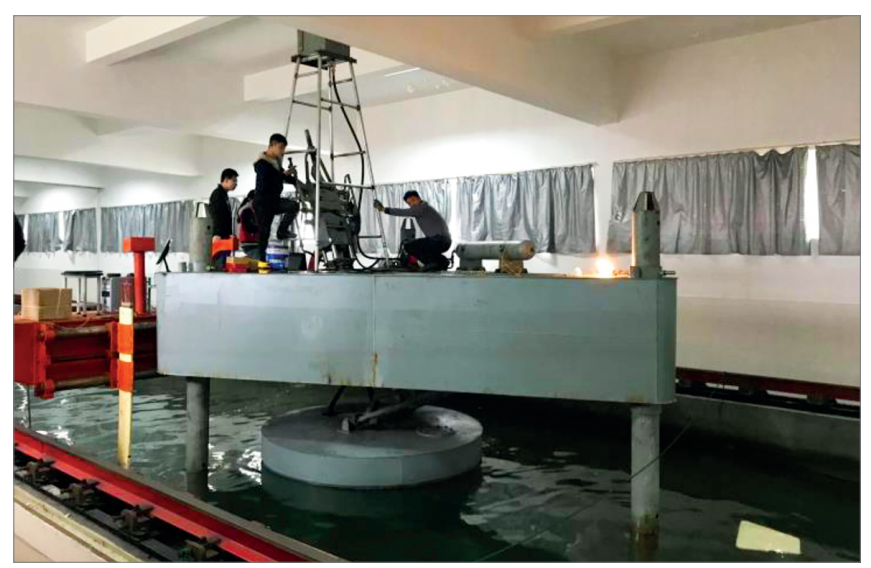

Fig. 12. Physical model of "Haida No. 1"

\section{EXPERIMENT AND RESULT ANALYSIS}

In order to verify the consistency of the numerical results, an optimized physical model as shown in Fig. 12 is established based on the numerical results. In the physical model, the arm length $L$ is $2.5 \mathrm{~m}$, the tilt angle $\alpha$ is $20^{\circ}$, the buoy width $D$ is $2 \mathrm{~m}$, the buoy draft $r$ is $1 \mathrm{~m}$, and the buoy freeboard $b$ is $0.5 \mathrm{~m}$. The laboratory pool is $130 \mathrm{~m}$ long, $6 \mathrm{~m}$ wide and $4 \mathrm{~m}$ deep. One

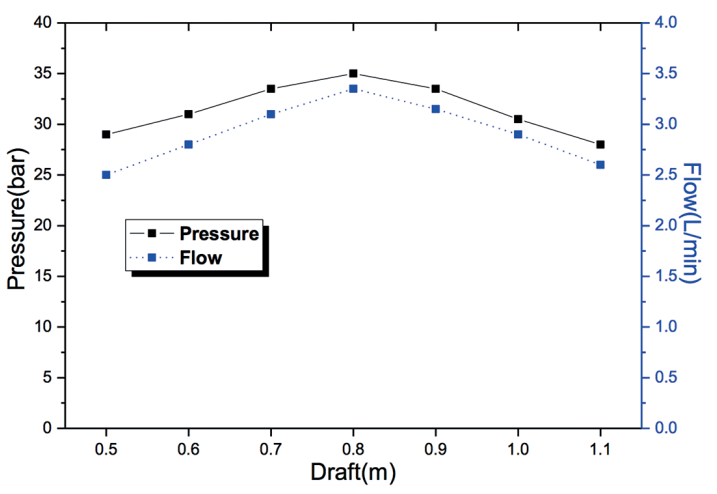

(a) Pressure and flow under different buoy drafts

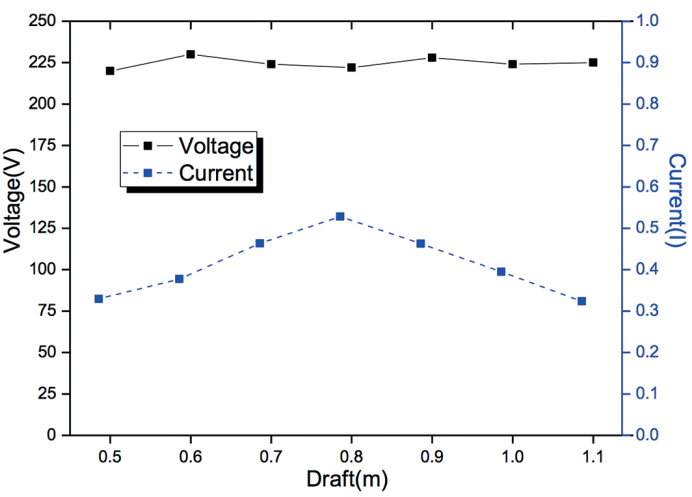

(b) Voltage and current under different buoy drafts

Fig. 13. Hydrodynamic performance of buoys under different buoy drafts 
end of the laboratory pool is equipped with a hydraulic swing wave maker, and the other end is equipped with a sponge layer wave eliminator. The "Haida No. 1" OBWEC is installed at a distance of $30 \mathrm{~m}$ from the wave maker, and the influence of the reflected wave on the device can be ignored under the action of the sponge layer wave eliminator.

Fig. 13a shows the change curve of the pressure and flow in the hydraulic system for different buoy drafts when the wave period is $2.4 \mathrm{~s}$ and the corresponding wave height is $0.29 \mathrm{~m}$. The product of pressure and flow in the hydraulic system represents the output power of the hydraulic system, which is proportional to the capture width ratio of the buoy. It can be seen from the curve in the figure that as the buoy's draft increases, both the pressure and the flow rate first increase and then decrease. When the ratio of the buoy draft to the wave height is close to 2.75 , the pressure and flow in the hydraulic system reach the maximum.

Fig. 13b shows the change curve of the output voltage and current for different buoy drafts when the wave period is $2.4 \mathrm{~s}$ and the corresponding wave height is $0.29 \mathrm{~m}$. The product of the output voltage and current represents the total power output by the device, which is proportional to the capture width ratio of the buoy. It can be seen from the curve in the figure that when the ratio of the buoy draft to the wave height is close to 2.75, the output power reaches the maximum value, and the output voltage is relatively stable.

From the above conclusions, the experimental results verify the consistency of the numerical results.

\section{CONCLUSION}

In this paper, the "Haida No. 1" OBWEC is used as the research object, and its working principle is introduced. In order to further improve the energy conversion efficiency of the device, the influence of the arm length, tilt angle, buoy draft, buoy width, wave height, and PTO damping on the hydrodynamic performance of the buoy is studied based on the motion equation of the buoy in the waves. A physical model of "Haida No. 1" is established based on the numerical results, and the consistency of the numerical results is verified through a series of physical experiments. Based on the above results, the following conclusions are obtained:

1. The arm length $L$ has a great influence on the hydrodynamic performance of the buoy. Under the same wave period, as the arm length increases, the hydrodynamic performance of the buoy first increases rapidly and then gradually remains unchanged. Therefore, when designing the arm length, it is necessary to choose a reasonable length to avoid wasting space with too long an arm, or reducing the hydrodynamic performance of the buoy with too short an arm.

2. The tilt angle $\alpha$ has a great influence on the hydrodynamic performance of the buoy. Under the same wave period, as the tilt angle increases, the hydrodynamic performance of the buoy first increases and then decreases. Within a certain range, as the wave period increases the optimal tilt angle gradually increases.
3. For the same wave period, as the buoy width $D$ increases, the hydrodynamic performance of the buoy first increases and then decreases. When the ratio of the wavelength to the buoy width is between 4 and 5, the hydrodynamic performance of the buoy is the best.

4. The buoy shape 2 has better hydrodynamic performance than the other three buoy shapes in the same conditions.

5. For the same wave period, as the buoy draft $r$ increases, the buoy's hydrodynamic performance first increases and then decreases. When the buoy draft is about 2.75 times the wave height, the hydrodynamic performance of the buoy is optimal.

6. The PTO damping coefficient corresponding to the optimal hydrodynamic performance of the buoy is only related to the wave period, not to the wave height.

The above conclusions can provide a guide for optimizing the buoy's hydrodynamic performance in similar WEC.

\section{ACKNOWLEDGEMENTS}

The authors acknowledge the National Natural Science Foundation of China (Grant: 51679217), and the Project of Ship Collaborative Innovation Centre of Jiangsu Province of China (Grant: HZ20180007).

\section{REFERENCES}

1. Panwar, N.L., S.C. Kaushik, and S. Kothari. 'Role of renewable energy sources in environmental protection: A review Renewable and Sustainable Energy', Reviews. 2011, doi: 10.1016/S1364-0321(99)00011-8.

2. Ellabban, O., H. Abu-Rub, and F. Blaabjerg. 'Renewable energy resources: Current status, future prospects and their enabling technology', Renewable and Sustainable Energy Reviews. 2014, doi: 10.1016/j.rser.2014.07.113.

3. Zheng, C.W., Q. Wang, and C.Y. Li. 'An overview of medium-to long-term predictions of global wave energy resources', Renewable and Sustainable Energy Reviews. 2017, doi: 10.1016/j.rser.2017.05.109.

4. Astariz, S., and G. Iglesias. 'The economics of wave energy: A review', Renewable and Sustainable Energy Reviews. 2015, doi: 10.1016/j.rser.2015.01.061.

5. Rosa-Santos, P., et al. 'The CECO wave energy converter: Recent developments', Renewable Energy. 2019, doi: 10.1016/j.renene.2019.02.081.

6. Zou, S., et al. 'Optimal control of wave energy converters', Renewable Energy. 2017, doi: 10.1016/j.renene.2016.11.036.

7. Zhang, W., and Y. Liu. 'Simulation and experimental study in the process of wave energy conversion', Polish Maritime Research. 2016, doi: 10.1515/pomr-2016-0056. 
8. Sheng, W. 'Wave energy conversion and hydrodynamics modelling technologies: A review', Renewable and Sustainable Energy Reviews. 2019, doi: 10.1016/j.rser.2019.04.030.

9. Rusu, E., and F. Onea. 'A review of the technologies for wave energy extraction', Clean Energy. 2018, doi: 10.1093/ ce/zky003.

10. Cordonnier, J., et al. 'SEAREV: Case study of the development of a wave energy converter', Renewable Energy. 2015, doi: 10.1016/j.renene.2015.01.061.

11. Zanuttigh, B., E. Angelelli, and J.P. Kofoed. 'Effects of mooring systems on the performance of a wave activated body energy converter', Renewable Energy. 2013, doi: 10.1016/j.renene.2013.02.006.

12. Sjolte, J., et al. 'Summary of performance after one year of operation with the lifesaver wave energy converter system', 10th European Wave and Tidal Energy Conference, Aalborg, Denmark, 2013.

13. Neary, V.S., et al. 'Classification systems for wave energy resources and WEC technologies', International Marine Energy Journal. 2018, doi: 10.36688/imej.1.71-79.

14. De Andrés, A.D., et al. 'Analysis of the geometric tunability of a WEC from a worldwide perspective', International Conference on Offshore Mechanics and Arctic Engineering. Vol. 45530. American Society of Mechanical Engineers, 2014.

15. Bedard, R., and G. Hagerman. 'E2I EPRI assessment offshore wave energy conversion devices', Electrical Innovation Institute: Washington, DC, USA, 2004.

16. Haraguchi, R., and T. Asai. 'Enhanced power absorption of a point absorber wave energy converter using a tuned inertial mass', Energy. 2020, doi: 10.1016/j.energy.2020. 117740.

17. Homayoun, E., H. Ghassemi, and H. Ghafari. 'Power performance of the combined monopile wind turbine and floating buoy with heave-type wave energy converter', Polish Maritime Research. 2019, doi: 10.2478/pomr-2019-0051.

18. Lai, W., D. Li, and Y. Xie. 'Simulation and experimental study of hydraulic cylinder in oscillating float-type wave energy converter', Polish Maritime Research. 2020, doi: 10.2478/ pomr-2020-0024.

19. Sjolte, J., et al. 'Exploring the potential for increased production from the wave energy converter lifesaver by reactive control', Energies. 2013, doi: 10.3390/en6083706.

20. Han, Z., Z. Liu, and H. Shi. 'Numerical study on overtopping performance of a multi-level breakwater for wave energy conversion', Ocean Engineering. 2018, doi: 10.1016/j. oceaneng.2017.12.058.
CONTACT WITH THE AUTHORS

\author{
Yonghe Xie \\ e-mail:xieyh@zjou.edu.cn \\ Zhejiang Ocean University \\ Dinghai, 316022 Zhoushan \\ China
}

Wenbin Lai

e-mail:630880804@qq.com

Zhejiang Ocean University

Dinghai, 316022 Zhoushan

China

Detang Li

e-mail: lidetang2008@163.com

Zhejiang Ocean University

Dinghai, 316022 Zhoushan

China 